\title{
Relationship between Wine Consumption and Alzheimer's Disease
}

Marcella Reale ${ }^{1 *}$, Chiara D’Angelo ${ }^{1}$, Erica Costantini ${ }^{1}$, Srinivas Jagarlapoodi ${ }^{1}$, Haroon $\operatorname{Khan}^{2}$, Tarun Belwal ${ }^{3}$, Angelo Cichelli ${ }^{1}$,

${ }^{1}$ Dept. of Medical, Oral and Biotechnological Sciences, University “G. d'Annunzio” ChietiPescara, Chieti, Italy

${ }^{2}$ Department of Pharmacy, Abdul Wali Khan University Mardan 23200, Pakistan

${ }^{3}$ Good.B. Pant National Institute of Himalayan Environment and Sustainable Development, Kosi-Katarmal, Almora, Uttarakhand, India

Running title: Wine and Alzheimer's disease

* Author to whom correspondence should be addressed; E-Mail: mreale@ unich.it

Prof. Marcella Reale

Dept. of Medical, Oral and Biotechnological Sciences, University "G. d'Annunzio" ChietiPescara, Chieti, Italy

Phone: +390872 3554029

There are no conflicts of interest. No financial support was given for the study.

\begin{abstract}
Background: Alzheimer's disease (AD), the most threatening neurodegenerative diseases, is characterized by the loss of memory and language function, an unbalanced perception of space and other cognitive and physical manifestations. Pathology of the AD is characterized by neuronal loss, and the extensive distribution of senile plaques and neurofibrillary tangles (NFTs). The role of environment and the diet in the $\mathrm{AD}$ is being studied actively, and nutrition is certainly one of the main factors playing a prominent role in the prevention of neurodegenerative
\end{abstract}


diseases. In this context, the relationship between dementia and wine use/abuse has received increased research interest in recent times, with varying and often conflicting results.

Scope and approach: This review aims to critically summarize the most recent studies conducted to clarify the relationship between wine drinking and $\mathrm{AD}$, as well as whether effects are influenced by quantity and/or frequency of drinking.

Key findings and Conclusion: Overall, based on the interpretation of various studies, it can be concluded that there is no indication that light to moderate alcohol drinking is detrimental to cognition and dementia, and it is not possible to define whether alcohol could be used as a means to reduce risk of developing AD.

Keywords: Alcohol consumption, Alzheimer's Disease; light to moderate wine consumption; Neurodegeneration.

\section{Introduction}

The history of wine begins around 8000 to 5000 A.C. in Armenia, Georgia and Iran, in the early Bronze Age evidence of wine production was found in the Middle East, and around the third millennium A.C. in Egypt. Wine production was improved considerably in ancient Greece and Rome, when was tied to myth of Dionysus/Bacchus. Wine is the important staple beverage for Romans, and the influence of the Romans on the other regions of Europe had made the wine a definite component of the Mediterranean diet. Wine production gradually increased and its consumption became popularized and, the Christian Church became a staunch supporter of the wine necessary for celebration of the Catholic Mass. Wine, forbidden in medieval Islamic cultures, was used as a distillate for medicinal and industrial purposes.

Throughout history, wine has often been a tool to manage health, was in fact prescribed as medicine to treat symptoms or to promote health by preventing the most common ailments. In Mesopotamia, the wine was used in various treatments and therapies and mixed with honey represented a frequent therapy for cough treatment. The Egyptians used the wine as a solvent, as a remedy for weakness, injuries, or as an appetizer. The ancient Greek physician Hippocrates, considered wine to be a key nutrient of a healthy diet and also prescribed its use as a sedative and 
as antiseptic [1]. Although many beneficial and negative effects of alcohol on health have been highlighted, there are still many discussions about the real properties of its components and its actions on cells and molecular interactions. The impact of wine on health is usually dosedependent and there is a fine line between the amount of alcohol that causes problems to organic systems and the amount that could be beneficial for the health.

Drinking alcohol is a socially accepted behaviour, and many people consume alcohol without experiencing any problems, but the number of people that drink in a harmful manner was growing. There are many different kinds of alcoholic drinks, with a different alcohol contents and, although alcohol is legal and widely available, drinks with higher concentrations of alcohol carry the risk of causing health problems more quickly and in smaller doses.

The wine contains the fermenting products of the yeast of the must or juice, pressed by the grapes, the fruit of the genus Vitis vinifera, that comprises up to 5,000 cultivated species, used in wine. After fermentation, wine conserves a complex mixture of different compounds involved its and quality. Wine has a varying concentration of water, alcohol and phenolic compounds, of which tannins, resveratrol, and quercetin have been the most studied, polysaccharides or other trace elements, different types of acids, and volatile compounds. The main bioactive polyphenols are flavanols, flavonols, anthocyanins, and resveratrol. Flavonoids include catechin, epicatechin, proanthocyanidins, flavones, anthocyanins [2]. Catechin and epicatechin, may represent up to $60 \%$ of total phenolic compounds, and are usually the most important flavanols in both grape skins and seeds, and their antioxidant mechanism is related to the inhibition of nuclear factor kappa-B (NF- $\mathrm{B})$, a transcription factor that activates inflammatory cytokines. Flavonols comprise compounds such as myricetin, quercetin, kaempferol, and rutin. Quercetin induces the activity of antioxidant enzymes such as heme oxygenase, glutathione S-transferase, and thioredoxin reductase, and by inhibiting $\mathrm{NF}-\kappa \mathrm{B}$ translocation to the nucleus and reduction of the expression of Toll-like receptors (TLR2 and TLR4) showed an anti-inflammatory activity [3]. The anthocyanins most commonly found in wines are delphinidin-3-glucoside, cyanidin-3glucoside, and malvidin-3-glucoside, with recognized antioxidant and antiinflammatory capacity, as well as resveratrol that is able to induce or repress inflammatory cytokines, such as tumor necrosis factor-alpha (TNF- $\alpha$ ), interleukin -1 $\beta$ (IL-1 $\beta$ ), and interleukin-6 (IL-6), modulating, in a balanced way, the inflammatory response, and to inhibit NF- $\mathrm{B}$ and inflammatory enzymes, such as the inducible isoforms of Nitric oxide synthase (iNOS) and cyclooxygenase-1 (COX-1) 
[4]. Tannins, another subgroup of phenols found in the skins and seeds of grapes, play an important role in the quality of wine, since they contribute to sensory aspects such as color, bitterness, and astringency and structure of the wine. Polyphenols possesses beneficial and therapeutic properties in prevention of neurodegeneration, aging, tumorigenesis, and metabolic disorders for example diabetes. In vitro studies and preclinical models have demonstrated the association of wine polyphenols with activation of antioxidant and anti-inflammatory mechanisms. Polyphenol also showed activity in the treatment of pathogen infection, hypertension, and cardiovascular diseases [5-8]. The predominant sugars present in grapes are glucose and fructose, while sucrose is present only in trace. Ethanol and carbon dioxide are obtained through the breakdown of sugars by yeast in the process of fermentation. The volatility of aromatic compounds was related with sugar concentrations. Generally, sweetness is detected at levels higher than $1 \%(\mathrm{w} / \mathrm{v})$ of overall sugars, and is influenced by several constituents, such as ethanol, acids and tannins. Next to sugars, organic acids are the most abundant solids present in wine. They are responsible for the taste, wine stability, color, and $\mathrm{pH}$. The principal organic acids found in grapes are tartaric, malic, and to a small extent, citric. Sun et al. identified 2-Oferuloyl tartaric acid as potential phosphodiesterase 4D inhibitor (PDE4D). PDE4D alters the function of calcium channels in the central nervous system and therefore can be considered one of the causes of Alzheimer's disease [9]. Although proteins are present in wines at low concentrations, and contribute little to their nutritional value, they are responsible for the clarity and stability of wines in association with other factors of non-protein origin, such as polyphenols, wine $\mathrm{pH}$ and the presence of polysaccharides. Nitrogenous compounds include ammonium cations and amino acids, peptides, and proteins that serve as nutrient for yeast and lactic acid bacteria. The most important mineral compounds in the wine are potassium, sodium, iron, phosphates, sulfate, and chloride. The composition of wine is summarized in Figure 1, and as of any natural biological material the presence of components varies over a significant range.

To date, consumption of wine is part of the Mediterranean diet, and is increasingly associated with the promotion of human health and the prevention of diseases mainly associated with mental and heart health. However, possible health benefits may exist only with moderate drinking, i.e., "Up to one drink per day for women and up to two drinks per day for men and only for adults with legal drinking age" as reported by Dietary Guidelines of the United States (2015). Moderate wine drinking was linked to higher blood levels of omega-3 fatty acids that protect 
against heart disease, metabolizing glucose, decreases cardiometabolic risk, while increasing levels of heme-oxygenase and preventing blood clotting which may protect the brain from stroke damage. Also the risk of developing dementia and depression, was suggested, could be reduced by moderate wine drinking [10].

In the elderly, wine represents a widespread habit, especially during meals, whereas other alcoholic beverages are drunk occasionally. Researches have indicated that the positive effects of red wine on health are based on the presence of antioxidants that attack free radicals with different mechanisms. The antioxidant potential of red wine has been highlighted by the results of the "French paradox" that describe how in the French population, despite a relatively high dietary intake of saturated fats, the incidence of cardiovascular disease is relatively low, probably linked to the consumption of red wine [11]. The "French paradox" may have its basis in an environment containing various key molecules, so that the benefits could be mainly attributable to the combined, additive or synergistic effects of alcohol with other wine components.

Researchers are working to uncover the relationship between the molecular and nutritional properties of wine and the biological actions and bioavailability of the $>200$ phenolic compounds present, with the social factors that stratify wine consumption and the numerous effects of alcohol alone. Although the benefits of polyphenols in fruit and vegetables are increasingly accepted, how wine, in particular red wine with its abundant content of phenolic acids and polyphenols, gives further health benefits, it has not yet been fully clarified.

Many of the disorders subsequent to alcohol intake are related to large amounts of alcohol. About $10 \%$ of the population drinks $75 \%$ of the alcohol consumed in the United States [12]. Thus, if moderate wine drinking may have some health benefits, excessive alcohol consumption increases the risk of several cancers, heart disease, other chronic diseases and mental health problems. Chronic alcohol consumption results in persistent changes in brain driving reduction of behavioral control and difficulty avoiding negative consequences. Alcohol has been examined as a risk factor for dementia and a relationship between alcohol consumption and dementia has been evidenced. Although it is known that chronic alcohol abuse results in significant activation of neurodegenerative processes [13] and the prevalence of alcohol-related dementia represent about $10 \%$ of all cases of dementia [14] it is not yet fully clarified whether light-to-moderate drinking may have any health benefits [15]. The relationship between the amount of alcohol intake and cognitive outcomes is complicated by differing definitions of 'High' levels of alcohol 
consumption, by the different duration of abuse, by age in which alcohol consumption begins, sex, and by alternation of binge and withdrawal periods.

Since a link between alcohol misuse and Alzheimer's disease (AD) has been described, and alcohol dependence is a significant and independent predictor of $\mathrm{AD}$ [16], this review was designed to examine the association between the wine intake and AD.

\section{Neurodegeneration and Alzheimer's Disease}

Neurodegenerative diseases are age-dependent and steadily increasing disorders, partly due to life-length extensions [17]. Neurodegenerative diseases constitute a group of diseases characterized by an irreversible and progressive loss of neuronal cells in certain areas of the brain, related with loss of movement cognitive and behavioral function. The main neurodegenerative diseases are Alzheimer's disease, Parkinson's disease, Amyotrophic Lateral Sclerosis Dementia and Huntington's disease, joined by some pathogenic and clinical characteristics. Dementia is responsible for the greatest burden of neurodegenerative diseases, and Alzheimer's represents approximately 60-70\% of dementia cases. According to the World Alzheimer's Report 2016, 46.8 million people in 2015 were affected by dementia, and an increase of up to 131.5 million is expected by 2050. Based on the neuropsychiatric assessment of clinical features and memory deficits, it is possible to diagnose only a probable $\mathrm{AD}$, while the certain diagnosis can only be made post-mortem with the analysis of cerebral degeneration [18]. Several factors, including genetic and environmental, concur each other to neurodegenerative diseases onset. Factors such as aging, diabetes mellitus, smoking habits, lower socio-economical engagement and APO-E are associated with increased risk of Alzheimer's development. While Mediterranean diet-adherence, light-to-moderate alcohol-consumption, high educational realization, physically and cognitively stimulating activities appear related with a decreased risk of Alzheimer's disease onset [19]. In the brain, the build-up of toxic proteins and a loss of mitochondrial function are the events that prelude to the progressive neuronal damage. Oxidative stress, linked to direct neuroinflammation, metal accumulation and mitochondrial dysfunction, played a crucial role in neurodegeneration [20,21]. The cascade of pathological events linked to neurodegeneration are characterized by a high production of free radicals that act on nucleic acids, proteins, and fats as well as on glycosylation of DNA and proteins, inducing apoptosis and necrosis. Proteins undergo structural and functional changes responsible for degradation and 
misfolding, such as $\beta$-amyloid (A $\beta$ ) in Alzheimer's disease and $\alpha$-synuclein in Parkinson's disease [22], proteins that in small quantities may also be present in elderly subjects. Oxidative stress elicits lipid peroxidation and derived products reacting with protein form intracellular precipitates, in addition, oxidative stress induces activation of glial cells that release proinflammatory cytokines strengthening the neurodegeneration.

Alzheimer's disease, a progressive and neurodegenerative disease, affect more than 5\% of the population over the age of 65 years. The neuropathology of AD is characterized by the presence intraneuronal deposits of neurofibrillary tangles, senile plaques around reactive microglia, deposits of amyloid beta, progressive loss of neurons and cerebral [23]. Neuronal death provokes memory failure, personality changes, and other manifestations. Brain inflammation is another hallmarks of Alzheimer disease (AD) [24], and is present from pre-clinical to terminal stages of the disease, as reflected by activated microglia and reactive astrocytes that surround plaques and secrete cytokine, thus enhancing the neuro-inflammatory response [25]. Emerging evidences suggest that inflammation plays a central role in $\mathrm{AD}$, and that $\mathrm{AD}$ pathogenesis is not restricted to the neuronal compartment, but also involves immunological mechanisms. In fact, high levels of pro-inflammatory cytokines have been found in the brain and cerebrospinal fluid, and increased peripheral blood levels of IL-1 $\beta$, IL-6, TNF- $\alpha$, TGF- $\beta$, and IL-18 suggest that AD may be associated with a more widespread inflammatory state [26-28].

Associated with the accumulation of $\mathrm{A} \beta$ and the deposition of neurofibrillary tangles, a significant oxidative damage increased production of reactive oxygen species (ROS), loss of mitochondrial function, altered metal homeostasis, and reduced antioxidant defense were detected in the brain of AD patients. Aberrant cellular metabolism could influence the production and accumulation of $\mathrm{A} \beta$ and hyperphosphorylated Tau protein, which separately could worsen mitochondrial dysfunction and ROS production, driving a vicious cycle. In addition, acetylcholinesterase (AChE) expression is substantially altered, and its activity is increased within and around the $\mathrm{A} \beta$ plaques but decreased in most brain regions of AD patients. Many studies are being performed to find a convincing relationship between obesity and neurodegenerative diseases and one of the major risk factors for dementia is metabolic syndrome and abdominal obesity correlated with deregulation of adipokines [29, 30]. 
It is evident that $\mathrm{AD}$ is a complex multifactorial syndrome and there is a general agreement that factors like smoking, physical exercise, lifestyle, diet, education and also may play an important role in the AD.

\section{Intake of alcoholic beverages: risk or protection of Alzheimer's disease?}

Albeit with different mechanisms, both no consumption or excessive, consumption of alcohol are both associated with an increased risk of dementia [31]. Deng et al. found the relation between drinking and risk of dementia, proving that elevated risk of cognitive impairment and high consumption of alcohol was related, and that reduced risk of dementia was related to light-tomoderate alcohol drinking [32].

$\mathrm{Xu}$ et al. reported a J-shaped relationship between alcohol intake and cognitive decline in MCI patients, and showed that the high consumption of alcoholic beverages as well as complete abstention increase the risk of dementia and that light-moderate alcohol drinking may be associated with a decreased risk of dementia [33]. Many studies have been conducted to clarify if alcohol may be a risk or protective factor for developing $\mathrm{AD}$, but the evidences are far from conclusive and the associations between abstinence, moderate or heavy drinking and risk of dementia remain unclear.

In general, the literature examining the impact of alcohol on AD, show several limitations such as the validity in measurement of alcohol consumption, period of time (day, month), consumption (continuous or variable), but above all the cognitive assessments of drinkers. It is also conceivable that environmental, socio-economic and lifestyles factors together with unknown causes of $\mathrm{AD}$ can contribute to the uncertainty of the role of wine intake in $\mathrm{AD}$. Cumulative evidence revealed that, also intermittent ethanol intake during the adolescence enhances the weakness of the brain to both ethanol-induced neural cell death and cognitive impairments. Studies on human alcoholic brain found a correlation between the rate and amount of lifetime alcohol consumption and whole brain damage and reduction in the number of neurons. Most studies did not distinguish among wine, beer or spirits, and studies that did make the distinction reported no difference among the effects of these different types of alcohol. Thus, only further and in-depth studies will clarify the intricate relationship between alcohol consumption and the onset of $\mathrm{AD}$ and clarify the risks or benefits involved in alcohol 
consumption, and the study if and how diet, and ingestion of wine, in particular, may help to slow the cognitive decline and protect against Alzheimer's regardless of other risk factors is very appealing.

\subsection{Moderate alcohol consumption}

There is evidence that moderate consumption of wine has a positive effect on organs and systems. Studies with rodent models and with cardiac myocytes and endothelial cells indicate that moderate alcohol intake can support anti-inflammatory processes involving adenosine receptors, protein kinase $\mathrm{C}(\mathrm{PKC})$ and nitric oxide synthase, which could drive cardio-protection. Collis et al., in their study, reported that the modifications of alcohol-related anti-inflammatory heat shock protein and protein kinase in the brain have similarities with those observed in the heart [34]. The recognition that dementia shares several risk factors with cardiovascular disease has encouraged studies on the association of alcohol intake with dementia. An inverse correlation between cardiovascular risk and moderate alcohol intake has been highlighted, which is nullified when consumption is high. Several systemic review were conducted to answer the question “Alcohol consumption is a protective factor against AD?". Taken together, the current literature does not provide adequate evidence for conclusive answer. A previous study reported that lightto-moderate/regular drinking have a protective effect against AD [32] while, other studies reported a protective effect of moderate-to-high levels of drinking, but a lot of variable such as age and sex, ethnicity, measures for alcohol, clinical evaluation, use of standardized cognitive assessments, do not allow to provide adequate conclusions [35-40]. The results of Zuccalà et al. showed that cognitive dysfunction is proportionally associated with the high or moderate alcohol consumption and sex [41]. An interesting longitudinal study has examined the association between alcohol consumption and dementia and showed that, in middle age non-drinkers have a greater risk of developing dementia than those who drink moderate amounts, with benefits particularly evident in wine drinkers. Cohort studies have pointed out that light or moderate alcohol consumption may reduce or not change significantly the risk for AD, as result of the presence of resveritol in red wine [42-44]. On the other hand, there is no evidence that consumption of alcohol between 1 unit/week and 14 units/week increases the risk of dementia, while consumption of alcohol >14 units/week increases the risk of dementia linearly with age. Thus risk of developing dementia progressively increased as the alcohol drinking increases. Even though men and women have a qualitatively and quantitatively different consumption of alcohol, 
no gender difference in alcohol effects on cognition was observed [45]. The Rotterdam study reported that in individuals aged 55 and older, the light to moderate drinking of alcohol (1-3 drinks per day) was correlated with a lower risk of dementia and that this outcome was not especially confined to any beverage type [46]. Others European investigations reported that a modest alcohol intake has been correlated with a reduced risk of dementia $[47,48]$.

Studies that have compared drinkers and non-drinkers reported that who drink at light-tomoderate levels exhibited lower lifetime risk for AD than those who abstained, and that both non-heavy drinkers and abstainers exhibited a decreased risk of AD [49]. The effect of moderate alcohol consumption for cognition was seen in both men and women, although the amount and pattern of drinking is very different between male and female. Overall, light to moderate drinking does not appear to impair cognition in younger subjects and actually seems to reduce the risk of dementia and cognitive decline in older subjects. The study of a cohort of individuals aged 65 and over, showed that light or moderate alcohol intake was associated with a lower risk of dementia and $\mathrm{AD}$, whereas beer and liquor intake was not associated with incident dementia. The analyzes stratified according to the presence of APOE-4 also showed that the association between the intake of light wine and the lower risk of the AD was limited to subjects without the APOE-4 allele. Thus, the presence of the APOE-4 allele appeared to eliminate the significantly reduced cognitive risk effect of moderate drinking [44]. The study on "binge" Finnish drinkers without the APOE-4 reported a not significantly reduced risk of dementia, while infrequent "binge" drinkers with APOE-4 had a significant increase in the risk of dementia [50]. The study performed to analyze the effect of alcohol and APOE-4, on the age of onset in Alzheimer's disease reported that the absence of APOE-4 allele in drinkers was associated with an earlier onset of $\mathrm{AD}$ [51]. While in women drinking moderately had a significantly reduced risk of cognitive decline independently of APOE-4 [52]. The question of whether the APOE-4 allele influences the "protective" effect of moderate ethanol on cognitive risk has not yet been resolved [44]. Because the glymphatic system plays a key role in the clearance of A $\beta 18$ and Tau23, proteins potentially neurotoxic, the effect of acute and chronic exposure to ethanol on glymphatic function has been investigated. A reduction in glypymphatic function resulting from levels of acute and chronic binge of alcohol intake and, surprisingly in mice treated with a low acute dose or a low chronic dose of alcohol, an increased glymphatic activity was observed. Thus, it may be hypothesized that the increase of glymphatic function combined with the reduction of glial 
fibrillary acidic protein expression, could play an important role in the reduction of risk of dementia in individuals who habitually intake low amounts of alcohol.

All studies confirm that positive effects become even more pronounced when a light-to-moderate wine consumption is associated with a healthy lifestyle and habits, such as the adoption of the Mediterranean diet and physical activity

Interestingly, using animal models has been shown that the synapse damage induced by amyloid$\beta$ and $\alpha$-synuclein may be counteracted by low concentrations of alcohol [53], and polyphenols, thanks to their antioxidant properties, might provide neuroprotection.

\subsection{High wine consumption}

It is well known that chronic intake of alcohol was linked, other than to a cardiac and liver problems, also to cognitive impairments and brain damage. Recently, the characteristics of dementia due to excessive alcohol drinking have received increased interest, and both neuropathological and imaging studies have suggested that excessive and prolonged use of alcohol may be responsible for structural and functional brain damage. In fact, chronic or excessive alchool consumption may cause damage in the temporal lobe similar to that observed in Alzheimer's diseases [54], and also the loss of white matter in the prefrontal cortex, corpus callosum, and cerebellum, and neuronal loss in the hypothalamus and cerebellum was observed [55].

Since the cholinergic system is linked with both alcohol intake and AD it is plausible that alcohol use could be linked to AD. Chronic alcohol use has been linked with degeneration of cholinergic neurons, as confirmed by positive effect of pharmacological manipulation of neuronal cholinergic pathway [56]. Additionally, alcohol may affect cognition by modulating the synthesis and release of acetylcholine in hippocampus, and may induce muscarinic and benzodiazepine receptor loss contributing to the cognitive deficits in $\mathrm{AD}[57,58]$.

In $\mathrm{AD}$, most of risk loci are located in or near genes that are predominantly expressed in microglia, confirming the hypothesis that microglia plays a decisive role in the AD progression. The microglial activation was detected in the brains of human alcoholics, but the debate whether microglial activation is the cause or consequence of alcohol-induced neurodegeneration is also open [59]. Toll-like receptors (TLRs), high-mobility group box 1 (HMGB1), miRNAs, pro-inflammatory cytokines and their receptors are involved in signaling 
between microglia, innate immune cells of the brain, and neurons in response to alcohol. Ethanol, at high concentrations, is capable of activating TLR4 signaling in astrocytes and microglia [60,61], and triggering the production of inflammatory mediators induces neuronal death. Ethanol that can activate microglial cells altering their morphology, phagocytic response, and production of inflammatory cytokines, such as TNF- $\alpha$ and IL-1 $\beta$, or inflammatory mediators such as nitric oxide (NO), can drive neurodegeneration. A recent study reported that ethanol, at physiological relevant concentrations, induces microglia activation and secretion of cytokines and inflammatory mediators [61]. Chronic ethanol treatment increases the production of cytokines and inflammatory mediators and induces neural cell death [62]. Several studies have demonstrated that conditioned medium of ethanol-treated microglia induced apoptosis in cultured neurons, in accord with observations that high levels of inflammatory mediators produced by activated microglia were deleterious for neurons [63-65]. Ethanol induce upregulation of COX-2 and iNOS expressions, the NO production in glial cells, [60, 66], and trigger signalling pathways that prime the production and expression of cytokines and inflammatory mediators, and cell death in the brain [62].

Taken together, the results of numerous studies indicate that neuroimmune signaling play a key role in the development of alcohol-related brain disorders. Chronic ethanol sensitizes both systemic and brain responses to neuroimmune-gene resulting in the hypothalamic-pituitaryadrenal- (HPA)-mediated enhancement of peripheral cytokines, which further exacerbates the neuroimmune response which increases neurodegeneration [67-70]. In addition to neuroimmune signaling, glutamate excitotoxicity also is linked to alcoholic neurodegeneration. Neuronal degeneration observed in adult brain after chronic alcohol exposure gave rise to the 'neurotoxicity' hypothesis according to which the chronic intake of alcohol can cause glutamate excitotoxicity and oxidative stress with neuronal loss [71]. To date if excitotoxicity is fundamental for neuro-destruction in adult models of chronic alcoholism it is only speculative, further studies are needed to prove it [72].

The effect of alcohol is also related to age, in fact the subjects who begin to consume alcohol before the age of 20 have deficits on multiple memory tasks that are more serious than those who start drinking after the age of 20 [73]. Heavy drinking during adolescence is associated with damage of prefrontal cortex and hippocampal area and with neurocognitive dysfunctions as well as in visuospatial, verbal and attention functions [74,75]. The study of Pascual et al. showed that, 
also during adolescence, intermittent ethanol intake induce inflammation and cell death in the neocortex, hippocampus and cerebellum, and cognitive impairment, supporting the role of inflammation in the ethanol-induced brain damage [76]. Overall, alcohol may support the genesis and sustenance of AD pathology via neuroinflammation.

Studies on animal have demonstrated that prolonged intake of alcohol induces alteration of in different area of brain such as hippocampus, hypothalamus, and cerebellum with impairments of cholinergic neurotransmission which plays a key role in attention, learning, and memory [77]. A critical role of the TLR4 response was confirmed by observation of microglia activation and neuroinflammatory damage induced by ethanol, and by microglia activation (CD11b cells) in cerebral cortex of $\mathrm{TLR}^{+/+}$mice, but not in TLR4 deficient mice after acute ethanol administration. According to these results, Fernandez-Lizarbe et al. [61] demonstrate that conditioned medium of ethanol-treated microglia induces apoptosis in cultured neurons. Growing evidence suggests that in rats, the alcohol intake related disorders alteration of brain circuitry are linked to neuroimmune signaling via Toll-like receptors (TLRs) [78].

Qin et al. have shown that, both 10 daily doses and an acute dose of ethanol induce a persistent increase in proinflammatory cytokines and microglial activation in the mice brain $[79$.

\section{Effects of components of wine on AD molecular target}

Importantly, although most studies have reported a nonsignificant association between risk of $\mathrm{AD}$ and wine intake, this does not necessarily mean that alcohol has no effect. In fact, the mechanisms by which wine intake may act to influence the risk of developing $\mathrm{AD}$ is not completely clarified.

When asked whether the effect of wine on health is attributed to ethanol, to micro-components of wine, or to their synergistic effect, a definitive answer has not yet been given. In fact, it is difficult to distinguish the action of one from that of more micro-components of wine. Even the use of alcohol-free wine has helped a lot because the bioavailability of the wine compounds can be changed in the absence of ethanol.

The possibly alcohol's beneficial effects were attributed principally to the polyphenols. Useful outcomes of polyphenols for $\mathrm{AD}$ have been principally reported in investigations with animal models for the $\mathrm{AD}$, considering the effects of fortified diets in specific polyphenols such as resveratrol, epigallocatechin-3-gallate, and quercetin [80-83] or in a mixture of polyphenols viz. 
grape seed extracts and red wine [84-86]. Dietary polyphenols including those present in grape products are considered promising neuromodulatory agents to fight AD because they have the ability to cross the blood-brain barrier; to protect neurons from neurotoxin-induced lesions; to attenuate the signaling cascade of oxidative/inflammatory stress in the brain; to interact with misfolded proteins/polypeptides preventing the formation of toxic aggregates; and to improve cognitive and memory skills [87] (Figure 2).

Recent studies have reported that promising health benefits from red wine consumption are due to resveratrol, whose amount in red wine can vary widely. Resveratrol has exhibited protective effects on neuron cell death induced by ethanol and other oxidative agents [88], and a powerful neuroprotective activity in focal cerebral ischemia [89]. Antioxidant and ion channel regulatory (Ca2p channels) properties of resveratrol provide neuroprotective effects. Lately, it has been published by Antonio et al. that resveratrol protects against ethanol-induced neurotoxicity [90]. Aruoma et al. [91] also reported that the low-molecular-weight proanthocyanidin dietary biofactor Oligonol also exhibited neuroprotective effects by modulating oxidative stress and additional factors [92].

Administering 3xTg-AD mouse model of Alzheimer's that displayed learning and memory deficits, with a low dose (100 mg GAE/ml) of a selected pool of wine polyphenolic compounds, with high antioxidant activity, boosts brain accumulation of several phenolic compounds such as catechin and hydroxybenzoic acid derivatives and induces significant benefits in multiple aspects of the pathophysiological cascade associated with progression of the neuropathology developed in the mice. Evidently, this diet has no undesired side effects on healthy controls, as suggested by the results obtained with Non-Tg mice. Therefore, polyphenolic-enriched nutrition may have the potential to benefit $\mathrm{AD}$ patient by modulating multiple disease-modifying mechanisms, rendering the stimulus for the development of polyphenolic compounds for AD treatment and/or prevention [93]. Resveratrol shows a broader range of beneficial effects targeting many molecular aspects of $\mathrm{AD}$ pathogenesis such as inhibition of $\mathrm{A} \beta$ fibrils formation [94,95], reduction of $A \beta$ production through sirtuin-dependent activation of a disintegrin and metalloproteinase domain-containing protein 10 [96], autophagic and lysosomal A $\beta$ degradation [97].

Resveratrol may interrupt the amyloid cascade acting as antioxidant and anti-inflammatory agent, reducing tau phosphorylation and deposition as well as $A \beta$-induced production of reactive 
oxygen species (ROS) [98]. Other than the free-radical scavenging abilities [99], resveratrol show ability to upregulate endogenous antioxidant enzymes such as superoxide dismutase (SOD), glutathione peroxidase (GPx), catalase (CAT) and heme oxygenase, and downregulate enzymes involved in the production of ROS, such as xanthine oxidase [100]. Resveratrol is able to counteract the production of mitochondrial ROS and to effectively eliminate hydroxyl, superoxide and metal-induced radicals, with the consequent strengthening of mitochondrial functioning and biogenesis through the activation of the SIRT1-PGC-1 $\alpha$ pathway, thus increasing mitochondrial bioenergetic efficiency [101-103]. Sirtuin-1 (SIRT1) activated by resveratrol induces direct deacetylation of tau to acetylate, promoting its proteasomal degradation [104], and also the phospho-tau toxicity (induced by cyclin-dependent kinase 5-p25 dependent tau phosphorylation) may be reduced by favoring the deacetylation of peroxisome proliferator-activated receptor gamma, coactivator 1 alpha (PGC- $1 \alpha$ ) and p53.

Resveratrol showed the ability to reduce the inflammatory status $[105,106]$ in in-vitro and in-vivo settings of neuroinflammation by inhibition of both interleukin- 8 and granulocyte-macrophage colony-stimulating factor release, the cytokine-stimulated iNOS expression, and the development of cytokine-producing $\mathrm{CD}^{+}$and $\mathrm{CD}^{+} \mathrm{T}$ cells by peripheral blood mononuclear cells $[107,108]$. Resveratrol is also known to interact with numerous proteins and pathways involved in the pathogenesis of obesity, including mitochondrial ATP synthase and complex III, fatty acid synthase, protein kinase $\mathrm{C}$, p53, a protein kinase activated by mitogen 1 , TNF- $\alpha$ and NF- $\kappa$ B. Recently Milne et al. reported that various resveratrol analogs are able to reduce insulin resistance by improving energy homeostasis [109]. In diabetic mice, it has been observed that the activation of AMP kinase by resveratrol protects against atherosclerosis and liver damage, suggesting a probable mechanism for the observations reported by De La Lastra and their colleagues [110].

Quercetin is found in wine that affects its color and taste, and in addition to this function, as molecule representative of flavonols it has many beneficial effects on the human health such as reduction of the risk of atherosclerosis by reducing LDL's, reduction of IL-1 $\beta$, C-reactive protein, and monocyte chemotactic protein-1 levels. Quercitin has been identified as one of the potent antioxidants, and $\mathrm{AD}$ can be benefited by the effective removal of reactive oxygen species. Quercetin induces a decrease in oxidative stress by increasing GSH levels in astrocytes 
and neurons, which is probably responsible for the reduction of $\mathrm{A} \beta$ and tau levels. In cell-free, cell-based and in silico studies, quercetin showed the ability to suppresses A $\beta$ synthesis [111]. Although it is known that quercetin is able to inhibit $\mathrm{A} \beta$ toxicity in vitro and in vivo, the detailed mechanisms are still elusive. It is reported that other than $\mathrm{A} \beta$ synthesis, quercetin also induces inhibition of formation and extension of $A \beta$ fibrils, added to this it also stimulates and destabilizes the preformed $A \beta$ fibrils $[112,113]$. The initial protein-protein interaction of $A \beta_{40}$ and $A \beta_{42}$ which has been proved to be necessary for $A \beta$ oligomerization, occurs with the interference of Quercetin-3-O-glucuronide [114]. Quercetin exerts neuroprotective effects against agent-induced toxicity [115] and increases the resistance of neurons to oxidative stress and excitotoxicity by modulating the mechanisms of cell death [116]. In addition, quercetin has an anti-inflammatory effect by inhibiting iNOS and regulating the expression of COX-2 [117].

Recent studies have reported that several signaling pathways, that participate in AD pathogenesis, such as cAMP-response element binding protein (CREB), c-Jun N-terminal kinases, the mitogen-activated protein, macroautophagy, calcium homeostasis, proteasomal degradation and GADD34-eIF2 $\alpha$-ATF4 pathways, may be modulated by quercetin and its metabolites [118,112]. Added to this quercetin has also a role to play as SIRT-1 agonist and AChE inhibitor to ameliorate AD phenotypes [119]. Quercetin acting as an antioxidant may show a promising protective effect in the $\mathrm{AD}$ and oxidative stress-related neurodegenerative.

Recent literature has showed that the Epigallocatechin-3-gallate (EGCG) may reduce the risk of various neurodegenerative diseases thanks to the different molecular signaling pathways present in its neuroprotective activity. EGCG demonstrates neuroprotective actions via MAPK, Akt, protein kinase $\mathrm{C}$ and $\alpha$-secretases [120]. EGCG also affects the processing of APP through multiple mechanisms, i.e. the non-amyloidogenic $\alpha$-secretase pathway, and also inhibits the $\beta$ secretase pathway that leads to the formation of $A \beta$ fibrils [121].

A $\beta$-induced cytotoxicity could be overcome by either the activation of the Akt signaling pathway [122] or by increasing the levels of acetylcholine in the presence of EGCG, which behaves as an acetylcholinesterase inhibitor. The neuroprotection upon $A \beta$-induced neuronal apoptosis could be achieved by effective removal of the reactive oxygen species. The rescue of the neuronal cells from Tau-induced neurotoxicity is possible as EGCC has the capacity to remold existing oligomers to an unfolded monomeric state $[123,124]$. 
So, dietary intake of EGCG, due to their interesting biological activities, and mostly to their antioxidant properties has been extensively studied regarding its potential beneficial effects in the AD. Oligonol, composed of catechin-type monomers and proanthocyanidin oligomers, is a polyphenolic compound derived from grape seed or lychee fruit with antioxidant and antiinflammatory activities. Recent studies have suggested that the antioxidant effects of oligonol were directly or indirectly associated with the activation of SIRT1. Oligonol also may downregulate mRNA expression related to iNOS, COX-2, NF- $\kappa$ Bp65, and oxidative stress. Since oxidative stress and inflammatory process are mainly associated with many neurodegenerative diseases, oligonol may show a protecting effect for neurodegeneration by its activity upon oxidative stress-induced inflammation [125].

\section{Different types of alcoholic beverages and AD}

The study of Heymann et al. [126] showed the link between AD and different type of alcoholic beverages. Hard liquor consumption is associated with a faster cognitive decline and exacerbation of the AD pathology. Contrasting results were reported about the effect of hard liquor and increased risk of $\mathrm{AD}[39,45,46,48,127]$. The mechanism by which hard liquor exerts this harmful effect on $\mathrm{AD}$ patients, may be due to the effects on the cholinergic system. Brain choline acetyltransferase (ChAT) and acetylcholinesterase (AChE) activities were reduced 9 days after ethanol exposure [128].

During the last years, mainly among young people, the beer is the most consumed beverage, and although, the composition of beer can be very different, and the contents of polyphenols, vitamins, minerals, protein and carbohydrates other than alcohol, is relevant. Several studies have analyzed the effect of beer consumption on dementia, and its protective effect against $\mathrm{Ab}$, aggregation in male brain was reported by Kok et al. [129]. Limited beer consumption decrease risk of $\mathrm{AD}$, probably by the protective effect of alcohol contained in the beer that may be correlated to signal transduction activation processes potentially involving ROS, protein kinases heat shock proteins [34]. In addition to antioxidant properties, the beer reduces the production of neopterin, the degradation of tryptophan and display the anti-inflammatory activity [130]. Hops, one of the raw materials of beer, and its extract inhibit the activity of $\gamma$-secretase and reduced $A \beta$ depositions in the cerebral cortex, hippocampus, and artery walls in the brains of AD model mice [131]. The presence of resveratrol in hops may improve the mitigation of memory impairment, 
and in general, phenolic acids present in the beer can inhibit the activity of cholinesterases and can regulate $A \beta$ aggregation, contributing to the neuroprotection. The iso- $\alpha$-acids, present in the beer, suppres inflammatory mediators and improve cognitive function. In fact, short-term intake of iso- $\alpha$-acids reduces TNF- $\alpha$, IL-12p40 and MIP-1 $\alpha$, and activates PPAR- $\gamma$ in the hippocampus improving memory impairment even after disease onset [132].

\section{Conclusion}

$\mathrm{AD}$ is a very common disease among aging individuals, the sixth leading cause of all death and one of the most common causes of impairment. One possible way to delay and/or prevent the onset of $\mathrm{AD}$ is by acting on its modifiable risk factors, amongst which diet plays an important role.

Since the wine consumption is constantly growing, numerous researches have been conducted to evaluate if alcohol might represent a modifiable risk factor for cognitive impairment. At present, there is no conclusive indication that alcohol use influences the risk of developing AD. If the excessive wine consumption, associated with adverse brain outcomes, may increase the risk of dementia by direct neurotoxic effects, the light to moderate wine consumption seems to reduce the risk of dementia and cognitive decline in age-dependent manner. Thus, the attenuation or protection or intensification of $\mathrm{AD}$ is based on the amount and frequency of wine consumption, by individual characteristics and their lifestyle. An emerging body of literature contends wine consumption may serve as a protective factor for cognitive decline and have pointed out that the health properties of wine are associated with polyphenolic content and their antioxidant properties.

Taking into account the increased frequency of $\mathrm{AD}$, drinking, due to alcohol content in the beverages, might not be adequate behavior for all people. In fact, based on the data presented, we cannot determine what could be the reasonable amount of alcohol that can be ingested and that protects against a negative effect.

\section{Figure Legends}




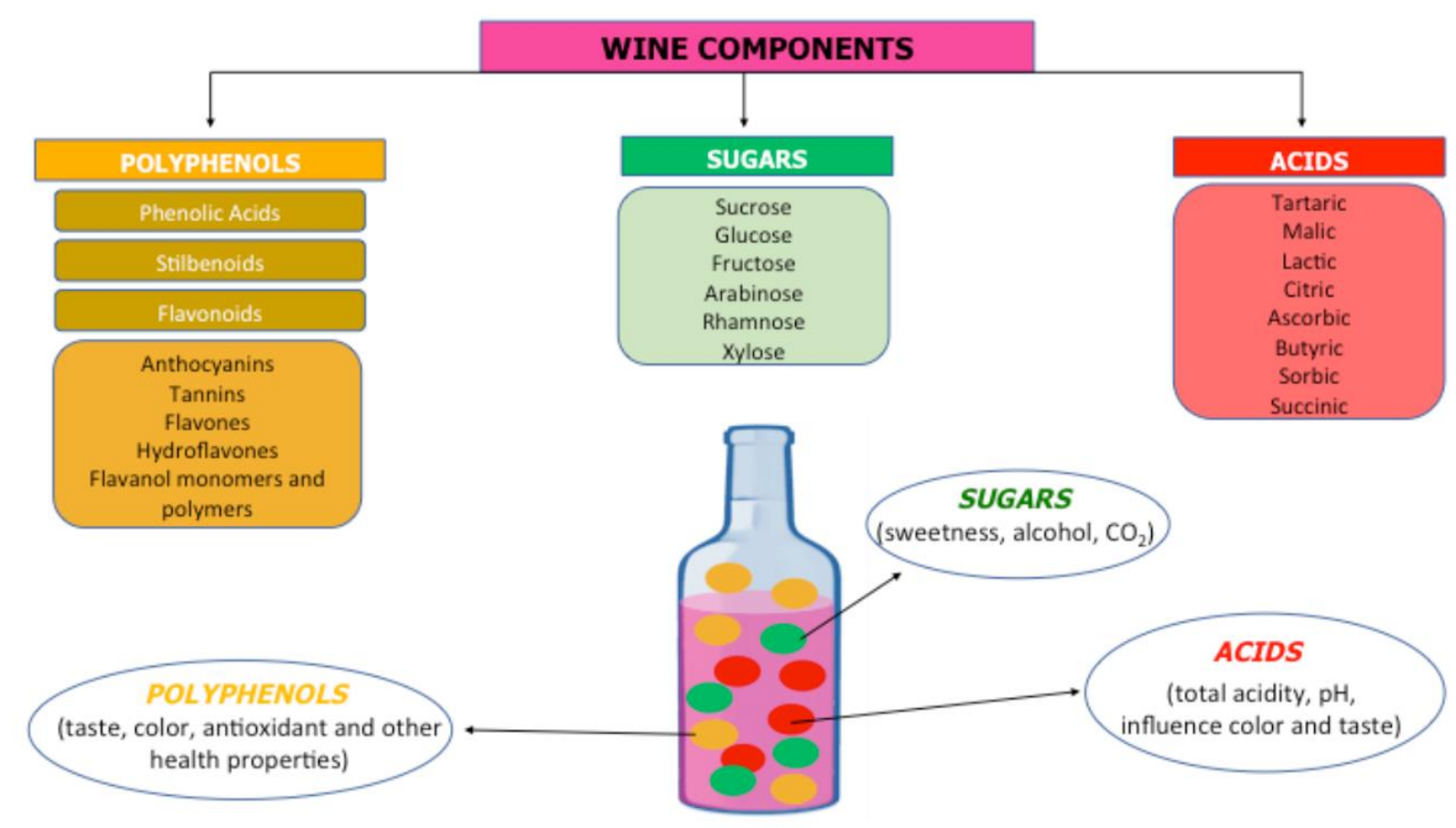

Figure 1. Several components of the wine

Neuroprotective action mainly due to Polyphenols

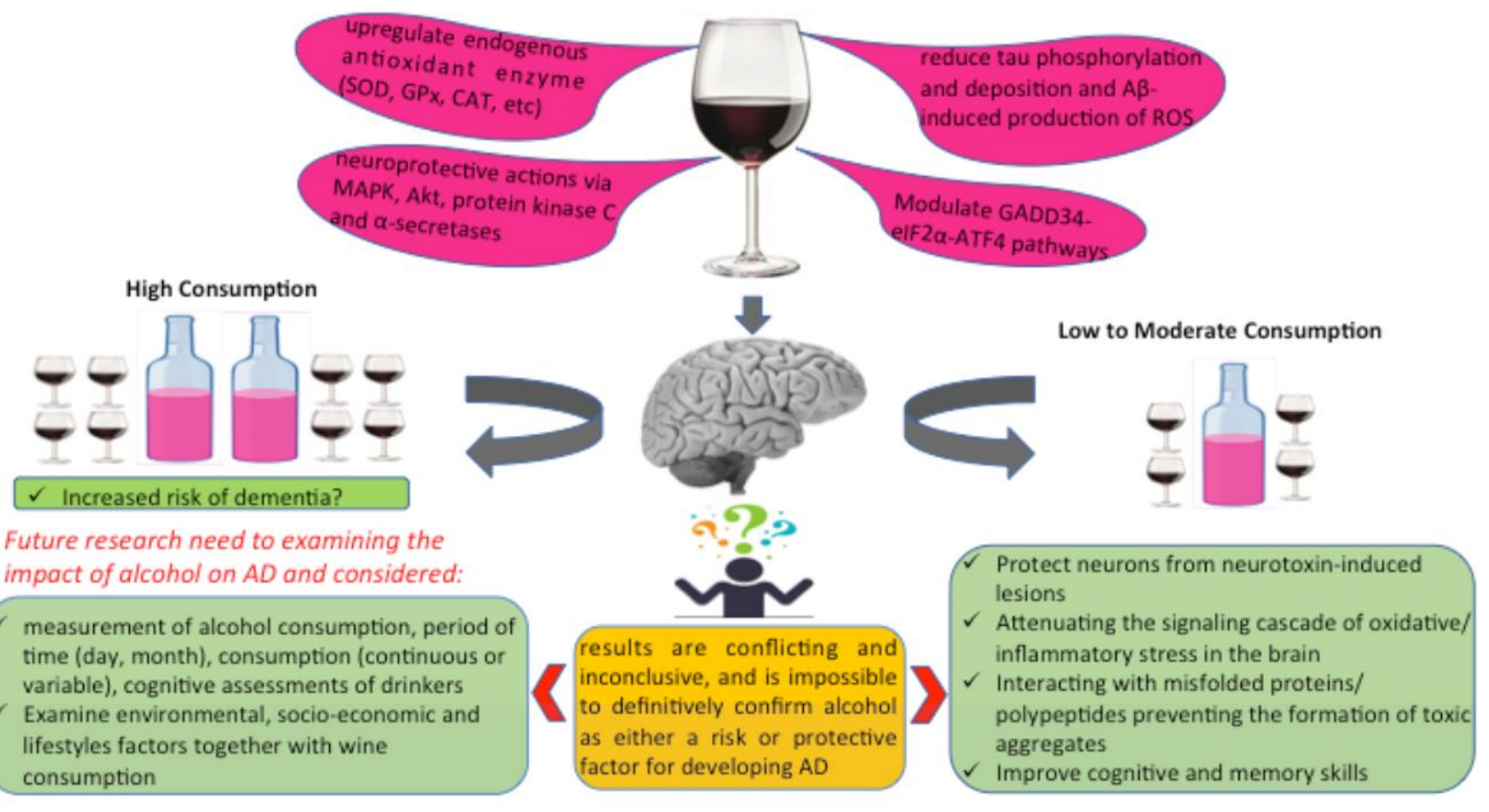

Figure 2. Different components of wine that may protect the brain 


\section{References}

1. Norrie, P. The History of Wine as a Medicine: From Its Beginnings in China to the Present Day. Cambridge Scholars Publishing. 2018.

2. Quideau, S.; Deffieux, D.; Douat-Casassus, C.; Pouysegu, L. Plant polyphenols: Chemical properties, biological activities and synthesis. Angew Chem Int Ed Engl. 2011. 17;50(3):586-621. doi: 10.1002/anie.201000044

3. Lesjak. M.; IvanaBeara, I.; Simin, N.; Pintać, D.; Majkić, T.; Bekvalac, K.; Orčić, D.; Mimica-Dukić, N. Antioxidant and anti-inflammatory activities of quercetin and its derivatives. Journal of Functional Foods. 2018.40, 68-75.

4. Salehi, B.; Mishra, A.P.; Nigam, M.; Sener, B.; Kilic, M.; Sharifi-Rad, M.; Fokou, P.V.T.; Martins, N.; Sharifi-Rad, J. Resveratrol: A Double-Edged Sword in Health Benefits. Biomedicines. 2018. 9;6(3). pii: E91. doi: 10.3390/biomedicines6030091

5. Khan, H.; Reale, M.; Ullah, H.; Sureda, A.; Tejada, S.; Wang, Y.; Zhang, Z.-J.; Xiao, J. Anticancer effects of polyphenols via targeting p53 signaling pathway: updates and future directions. Biotechnology Advances. 2019.

6. Khan, H.; Sureda, A.; Belwal, T.; Çetinkaya, S.; Süntar, İ.; Tejada, S.; Devkota, H.P.; Ullah, H.; Aschner, M. Polyphenols in the treatment of autoimmune diseases. Autoimmunity Review. 2019.18, 647-657.

7. Rengasamy, K.R.R.; Khan, H.; Gowrishankar, S.; Lagoa, R.J.L.; Mahomoodally, F.M.; Khan, Z.; Suroowan, S.; Tewari, D.; Zengin, G.; Hassan, S.T.S.; Pandian, S.K. The role of flavonoids in autoimmune diseases: Therapeutic updates. Pharmacology and Therapeutics. 2019.194, 107-131.

8. Ullah, H.; Khan, H. Anti-Parkinson Potential of Silymarin: Mechanistic Insight and Therapeutic Standing. Frontiers in Pharmacology 2018. 9.

9. Sun, Z-K.; Yang, H-Q.; Chen, S-D. Traditional Chinese medicine: a promising candidate for the treatment of Alzheimer's disease. Transl Neurodegener. 2013. 2(1):6. doi:10.1186/2047-9158-2-6

10. Nooyens, A.C.; Bueno-de-Mesquita, H.B.; van Gelder, B.M.; van Boxtel, M.P.; Verschuren, W.M. Consumption of alcoholic beverages and cognitive decline at middle age: the Doetinchem Cohort Study. British Journal of Nutrition. 2014. 111, 715-723.

11. Lippi, G.; Franchini, M.; Favaloro, E.J.; Targher, G. Moderate red wine consumption and cardiovascular disease risk: beyond the "French paradox", Seminars in thrombosis and hemostasis. ${ }^{\odot}$ Thieme Medical Publishers 2010. 059-070.

12. Stockley, C.S. Wine consumption, cognitive function and dementias-A relationship? Nutrition and Aging. 2015. 3, 125-137.

13. Vetreno, R.P.; Yaxley, R.; Paniagua, B.; Johnson, G.A.; Crews, F.T.; Adult rat cortical thickness changes across age and following adolescent intermittent ethanol treatment. Addiction Biology. 2017. 22, 712-723.

14. Gupta, S.; Warner, J. Alcohol-related dementia: a 21st-century silent epidemic? The British Journal of Psychiatry. 2008. 193, 351-353.

15. Shokri-Kojori, E.; Tomasi, D.; Wiers, C.E.; Wang, G-J.; Volkow, N.D. Alcohol affects brain functional connectivity and its coupling with behavior: greater effects in male heavy drinkers. Molecular Psychiatry. 2017. 22, 1185. 
16. Venkataraman, A.; Kalk, N.; Sewell, G.; Ritchie, CW.; Lingford-Hughes, A. Alcohol and Alzheimer's Disease-Does Alcohol Dependence Contribute to Beta-Amyloid Deposition, Neuroinflammation and Neurodegeneration in Alzheimer's Disease? Alcohol Alcohol. 2017. 52(2),151-158. doi: 10.1093/alcalc/agw092

17. Heemels, M-T. Neurodegenerative diseases. Nature. 2016. 539, 179.

18. McKhann, G.M.; Knopman, D.S.; Chertkow, H.; Hyman, B.T.; Jack Jr, C.R.; Kawas, C.H.; Klunk, W.E.; Koroshetz, W.J.; Manly, J.J.; Mayeux, R. The diagnosis of dementia due to Alzheimer's disease: Recommendations from the National Institute on AgingAlzheimer's Association workgroups on diagnostic guidelines for Alzheimer's disease. Alzheimer's and Dementia. 2011. 7, 263-269.

19. Hersi, M.; Irvine, B.; Gupta, P.; Gomes, J.; Birkett, N.; Krewski, D. Risk factors associated with the onset and progression of Alzheimer's disease: A systematic review of the evidence. Neurotoxicology. 2017, 61, 143-187

20. Reale, M.; A Kamal, M.; Velluto, L.; Gambi, D.; Di Nicola, M.; H Greig, N. Relationship between inflammatory mediators, $A \beta$ levels and ApoE genotype in Alzheimer disease. Current Alzheimer Research. 2012. 9, 447-457.

21. Regen, F.; Hellmann-Regen, J.; Costantini, E.; Reale, M. Neuroinflammation and Alzheimer's disease: implications for microglial activation. Current Alzheimer Research. 2017.14, 1140-1148.

22. Soto, C.; Estrada, L.D. Protein misfolding and neurodegeneration. Archives of Neurology. 2008. 65, 184-189.

23. Lavretsky, H.; Siddarth, P.; Kepe, V.; Ercoli, L.M.; Miller, K.J.; Burggren, A.C.; Bookheimer, S.Y.; Huang, S-C.; Barrio, J.R.; Small, G.W. Depression and anxiety symptoms are associated with cerebral FDDNP-PET binding in middle-aged and older nondemented adults. American Journal of Geriatric Psychiatry. 2009.17, 493-502.

24. Akiyama, H. Inflammation and Alzheimer's disease. Neurobiol Aging. 2000. 21(3),383-421. doi:10.1016/S0197-4580(00)00124-X

25. Heneka, M.T.; Carson, M.J.; El Khoury, J.; Landreth, G.E.; Brosseron, F.; Feinstein, D.L., et al. Neuroinflammation in Alzheimer's disease. Lancet Neurol. 2015. 14(4), 388-405. doi:10.1016/S1474-4422(15)70016-5

26. Reale, M.; Brenner, T.; Greig, N.H.; Inestrosa, N.; Paleacu, D. Neuroinflammation, AD, and Dementia. Int J Alzheimers Dis. 2010. 974026.

27. Reale, M.; Iarlori, C.; Gambi, F.; Lucci, I.; Salvatore, M. Acetylcholinesterase inhibitors effects on oncostatin-M, interleukin-1 beta and interleukin-6 release from lymphocytes of Alzheimer's disease patients. Exp Gerontol. 2005. 40(3),165-71. ID 974026;

28. Iarlori, C.; Gambi, D.; Gambi, F.; Lucci, I.; Feliciani, C.; et al. Expression and production of two selected beta-chemokines in peripheral blood mononuclear cells from patients with Alzheimer's disease. Exp Gerontol. 2005. 40(7), 605- 11

29. Parimisetty, A.; Dorsemans, A-C.; Awada, R.; Ravanan, P.; Diotel, N.; d'Hellencourt, C.L. Secret talk between adipose tissue and central nervous system via secreted factors-an emerging frontier in the neurodegenerative research. Journal of Neuroinflammation. 2016. 13, 67-73.

30. Teixeira, A.L.; Diniz, B.S.; Campos, A.C.; Miranda, A.S.; Rocha, N.P.; Talib, L.L.; Gattaz, W.F.; Forlenza, O.V. Decreased levels of circulating adiponectin in mild cognitive impairment and Alzheimer's disease. Neuromolecular Medicine. 2013.15, 115-121. 
31. Sabia, S.; Fayosse, A.; Dumurgier, J.; Dugravot, A.; Akbaraly, T.; Britton, A.; Kivimäki, M.; Singh-Manoux, A. Alcohol consumption and risk of dementia: 23 year follow-up of Whitehall II cohort study. British Medical Journal. 2018. 362, k2927.

32. Deng, J.; Zhou, D.H.; Li, J.; Wang, Y.J.; Gao, C.; Chen, M.E. A 2-year follow-up study of alcohol consumption and risk of dementia. Clinical Neurology and Neurosurgery. 2006.108, 378-383.

33. Xu, G.; Liu, X.; Yin, Q.; Zhu, W.; Zhang, R.; Fan, X. Alcohol consumption and transition of mild cognitive impairment to dementia. Psychiatry and Clinical Neurosciences. 2009. 63, 43-49.

34. Collins, M.A.; Neafsey, E.J.; Mukamal, K.J.; Gray, M.O.; Parks, D.A.; Das, D.K.; Korthuis, R.J. Alcohol in moderation, cardioprotection, and neuroprotection: epidemiological considerations and mechanistic studies. Alcoholism: Clinical and Experimental Research. 2009. 33, 206-219.

35. Piazza-Gardner, A.K.; Gaffud, T.J. Barry AE. The impact of alcohol on Alzheimer's disease: a systematic review. Aging Ment Health. 2013. 17(2),133-46;

36. Shield, K.D.; Parry, C.; Rehm, J. Chronic diseases and conditions related to alcohol use. Alcohol Research. 2014. 35, 155-73.

37. Anstey, K.J.; Peters, R. Alcohol and dementia: risk or protective factor? Nature Reviews Neurology. 2018. doi:10.1038/s41582-018-0073-0;

38. Anstey, K.J.; Mack, H.A.; Cherbuin, N. Alcohol consumption as a risk factor for dementia and cognitive decline: meta-analysis of prospective studies. Am. J. Geriatr. Psychiatry. 2009. 17, 542-555

39. Sabia, S.; Fayosse, A.; Dumurgier, J.; Dugravot, A.; Akbaraly, T.; Britton, A.; Kivimäki, M.; Singh-Manoux, A. Alcohol consumption and risk of dementia: 23 year follow-up of Whitehall II cohort study. BMJ 2018. 362, k2927

40. Neafsey, E.J.; Collins, M.A. Moderate alcohol consumption and cognitive risk. Neuropsychiatr Dis Treat. 2011. 7: 465-484

41. Zuccalà, G.; Onder, G.; Pedone, C.; Cesari, M.; Landi, F.; Bernabei, R.; Cocchi, A. DoseRelated Impact of Alcohol Consumption on Cognitive Function in Advanced Age: Results of a Multicenter Survey. Alcohol Clin Exp Res. 2001. 25, 12, 1743-1748

42. Larkin, J.P.; Seltzer, B. Alcohol abuse and Alzheimer's disease. Hosp Community Psychiatry. 1994. 45, 1040-1041;

43. Letenneur, L.; Risk of dementia and alcohol and wine consumption: a review of recent results. Biol Res. 2004. 37, 189-193

44. Luchsinger, J.A.; Tang, M.X.; Siddiqui, M.; Shea, S.; Mayeux, R. Alcohol intake and risk of dementia. Journal of the American Geriatrics Society. 2004. 52, 540-546.

45. Mehlig, K.; Skoog, I.; Guo, X.; Schütze, M.; Gustafson, D.; Waern, M.; Östling, S.; Björkelund, C.; Lissner, L. Alcoholic beverages and incidence of dementia: 34-year follow-up of the prospective population study of women in Göteborg. American Journal of Epidemiology. 2008. 167, 684-691.

46. Ruitenberg, A.; van Swieten, J.C.; Witteman, J.C.; Mehta, K.M.; van Duijn, C.M.; Hofman, A.; Breteler, M.M. Alcohol consumption and risk of dementia: the Rotterdam Study. The Lancet. 2002. 359, 281-286.

47. Huang, W.; Qiu, C.; Winblad, B.; Fratiglioni, L. Alcohol consumption and incidence of dementia in a community sample aged 75 years and older. Journal of Clinical Epidemiology. 2002. 55, 959-964. 
48. Truelsen, T.; Thudium, D.; Grønbæk, M.; Amount and type of alcohol and risk of dementia: the Copenhagen City Heart Study. Neurology. 2002. 59, 1313-1319.

49. Weyerer, S.; Schäufele, M.; Wiese, B.; Maier, W.; Tebarth, F.; van den Bussche, H.; Pentzek, M.; Bickel, H.; Luppa, M.; Riedel-Heller, S.G. Current alcohol consumption and its relationship to incident dementia: results from a 3-year follow-up study among primary care attenders aged 75 years and older. Age and Ageing. 2011. 40, 456-463.

50. Anttila, T.; Helkala, E.L.; Viitanen, M.; Kåreholt, I.; Fratiglioni, L.; Winblad, B.; Soininen, H.; Tuomilehto, J.; Nissinen, A.; Kivipelto, M. Alcohol drinking in middle age and subsequent risk of mild cognitive impairment and dementia in old age: a prospective population based study. British Medical Journal. 2004. 329 (7465), 539.

51. Harwood, D.G.; Kalechstein, A.; Barker, W.W.; Strauman, S.; St. George-Hyslop, P.; Iglesias, C.; Loewenstein, D.; Duara, R. The effect of alcohol and tobacco consumption, and apolipoprotein E genotype, on the age of onset in Alzheimer's disease. International Journal of Geriatric Psychiatry. 2010. 25, 511-518.

52. Stampfer, M.J.; Kang, J.H.; Chen, J.; Cherry, R.; Grodstein, F. Effects of moderate alcohol consumption on cognitive function in women. New England Journal of Medicine. 2005. 352, 245-253.

53. Bate, C.; Williams, A. Ethanol protects cultured neurons against amyloid- $\beta$ and $\alpha$-synucleininduced synapse damage. Neuropharmacology. 2011. 61, 1406-1412.

54. Pfefferbaum, A.; Lim, K.O.; Zipursky, R.B.; Mathalon, D.H.; Rosenbloom, M.J.; Lane, B.; Ha, C.N.; Sullivan, E.V. Brain gray and white matter volume loss accelerates with aging in chronic alcoholics: A quantitative MRI study. Alcohol Clin. Exp. Res. 1992, 16, 10781089

55. Harper, C., Matsumoto, I. Ethanol and brain damage. Current Opinion in Pharmacology. 2005. 5, 73-78.

56. Arendt, T. Impairment in memory function and neurodegenerative changes in the cholinergic basal forebrain system induced by chronic intake of ethanol. J Neural Transm. 1994. 44, 173-187

57. Tyas, SL. Alcohol use and the risk of developing Alzheimer's disease. Alcohol Res Health. 2001. 25, 299-306

58. Freund, G.; Ballinger, W.E. Alzheimer's disease and alcoholism: possible interactions. Alcohol. 1992. 9, 233-240

59. Marshall, S.A.; McClain, J.A.; Kelso, M.L.; Hopkins, D.M.; Pauly, J.R.; Nixon, K. Microglial activation is not equivalent to neuroinflammation in alcohol-induced neurodegeneration: The importance of microglia phenotype. Neurobiol. Dis. 2013, 54, 239-251

60. Blanco, A.M.; Valles, S. L.; Pascual, M.; Guerri, C. Involvement of TLR4/type I IL-1 receptor signaling in the induction of inflammatory mediators and cell death induced by ethanol in cultured astrocytes. J. Immunol. 2005. 175, 6893-6899;

61. Fernandez-Lizarbe, S.; Pascual, M.; Guerri, C. Critical Role of TLR4 Response in the Activation of Microglia Induced by Ethanol. J Immunol. 2009. 183, 4733-4744

62. Valles, S.L.; Blanco A.M.; Pascual, M.; Guerri, C. Chronic ethanol treatment enhances inflammatory mediators and cell death in the brain and in astrocytes. Brain Pathol. 2004. $14,365-371$ 
63. Boyadjieva, N.I.; Sarkar, D.K. Role of microglia in ethanol's apoptotic action on hypothalamic neuronal cells in primary cultures. Alcohol Clin Exp Res. 2010. 34(11),1835-1842. doi:10.1111/j.1530-0277.2010.01271.x;

64. Boyadjieva, N.I.; Sarkar, D.K. Microglia play a role in ethanol-induced oxidative stress and apoptosis in developing hypothalamic neurons. Alcohol Clin Exp Res. 2013. 37(2),252262. doi:10.1111/j.1530-0277.2012.01889.x;

65. Kawabori, M.; Yenari, M.A. The role of the microglia in acute CNS injury. Metab Brain Dis. 2015. 30(2), 381-392. doi:10.1007/s11011-014-9531-6

66. Blanco, A.M.; Pascual, M.; Valles, S.L.; Guerri, C. Ethanol-induced iNOS and COX-2 expression in cultured astrocytes via NF-kappa B. Neuroreport. 2004. 15(4), 681-685

67. Crews, F.T.; Sarkar, D.K.; Qin, L.; Zou, J.; Boyadjieva, N.; Vetreno, R.P. Neuroimmune Function and the Consequences of Alcohol Exposure. Alcohol Res. 2015. 37(2), 331-41, 344-51;

68. Crews, F.T.; Lawrimore, C.J.; Walter, T.J.; Coleman, L.G.Jr. The role of neuroimmune signaling in alcoholism. Neuropharmacology. 2017. 122, 56-73.

69. Gano, A.; Doremus-Fitzwater, T.L.; Deak, T. Sustained alterations in neuroimmune gene expression after daily, but not intermittent, alcohol exposure. Brain Res. 2016. 1646, 6272. d

70. Noor, S.; Milligan, E.D. Lifelong Impacts of Moderate Prenatal Alcohol Exposure on Neuroimmune Function. Front Immunol. 2018. 9, 1107.

71. Bates, M.E.; Bowden, S.C.; Barry, D. Neurocognitive impairment associated with alcohol use disorders: implications for treatment. Experimental and Clinical Psychopharmacology. 2002. 10, 193-212

72. Collins, M.; Neafsey, E. Alcohol, Excitotoxicity and Adult Brain Damage: An Experimentally Unproven Chain-of-Events. Front Mol Neurosci. 2016. 9: 8

73. Salas-Gomez, D.; Fernandez-Gorgojo, M.; Pozueta, A.; Diaz-Ceballos, I.; Lamarain, M.; Perez, C.; Sanchez-Juan, P. Binge Drinking in Young University Students Is Associated with Alterations in Executive Functions Related to Their Starting Age. PLoS One. 2016. 11(11):e0166834

74. Brown, S.A.; Tapert, S.F.; Granholm, E.; Delis, D.C. Neurocognitive functioning of adolescents: effects of protracted alcohol use. Alcohol. Clin. Exp. Res. 2000. 24, 164-171

75. White, A.M.; Swartzwelder, H.S. Age-related effects of alcohol on memory and memoryrelated brain function in adolescents and adults. Recent Dev. Alcohol. 2005. 17, 161-176

76. Pascual, M.; Blanco, A.M.; Cauli, O.; Minarro, J.; Guerri, C. Intermittent ethanol exposure induces inflammatory brain damage and causes long-term behavioural alterations in adolescent rats. European Journal of Neuroscience. 2007. 25, 541-550,

77. Crews, F.T.; Collins, M.A.; Dlugos, C.; Littleton, J.; Wilkins, L.; Neafsey, E.J.; Pentney, R.; Snell, L.D.; Tabakoff, B.; Zou, J. Alcohol-induced neurodegeneration: when, where and why? Alcoholism: Clinical and Experimental Research. 2004. 28, 350-364.

78. Randall, P.A.; Vetreno, R.P.; Makhijani, V.H.; Crews, F.T.; Besheer, J. The Toll-Like Receptor 3 Agonist Poly(I:C) Induces Rapid and Lasting Changes in Gene Expression Related to Glutamatergic Function and Increases Ethanol Self-Administration in Rats. Alcohol Clin Exp Res. 2019. 43(1),48-60.

79. Qin, L.; He, J.; Hanes, R.N.; Pluzarev, O.; Hong, J.S.; Crews, F.T. Increased systemic and brain cytokine production and neuroinflammation by endotoxin following ethanol treatment. J. Neuroinflammation. 2008. 5, 10 
80. Park, E.J.; Pezzuto, J.M. The pharmacology of resveratrol in animals and humans. Biochimica et Biophysica Acta. 2015. 1852, 1071-1113.

81. Pasinetti, G.M.; Wang, J.; Ho, L.; Zhao, W.; Dubner, L. 2015. Roles of resveratrol and other grape-derived polyphenols in Alzheimer's disease prevention and treatment. Biochim Biophys Acta. 2015. 1852(6), 1202-8.

82. Rezai-Zadeh, K.; Shytle, D.; Sun, N.; Mori, T.; Hou, H.; Jeanniton, D.; Ehrhart, J.; Townsend, K.; Zeng, J.; Morgan, D. Green tea epigallocatechin-3-gallate (EGCG) modulates amyloid precursor protein cleavage and reduces cerebral amyloidosis in Alzheimer transgenic mice. Journal of Neuroscience. 2005. 25, 8807-8814.

83. Sabogal-Guáqueta, A.M.; Munoz-Manco, J.I.; Ramírez-Pineda, J.R.; Lamprea-Rodriguez, M.; Osorio, E.; Cardona-Gómez, G.P. The flavonoid quercetin ameliorates Alzheimer's disease pathology and protects cognitive and emotional function in aged triple transgenic Alzheimer's disease model mice. Neuropharmacology. 2015. 93, 134-145.

84. Ho, L.; Chen, L.H.; Wang, J.; Zhao, W.; Talcott, S.T.; Ono, K.; Teplow, D.; Humala, N.; Cheng, A.; Percival, S.S.. Heterogeneity in red wine polyphenolic contents differentially influences Alzheimer's disease-type neuropathology and cognitive deterioration. Journal of Alzheimer's Disease. 2009. 16, 59-72.

85. Pasinetti, G.M.; Ho, L. Role of grape seed polyphenols in Alzheimer's disease neuropathology. Nutrition and dietary. 2010. 2, 97-103

86. Wang, J.; Ho, L.; Zhao, W.; Ono, K.; Rosensweig, C.; Chen, L.; Humala, N.; Teplow, D.B.; Pasinetti, G.M. Grape-derived polyphenolics prevent A $\beta$ oligomerization and attenuate cognitive deterioration in a mouse model of Alzheimer's disease. Journal of Neuroscience. 2008. 28, 6388-6392.

87. Vauzour, D. 2012. Dietary polyphenols as modulators of brain functions: biological actions and molecular mechanisms underpinning their beneficial effects. Oxid Med Cell Longev. 2012. 2012, 914273.

88. Harikumar, K.B.; Aggarwal, B.B. Resveratrol: a multitargeted agent for age-associated chronic diseases. Cell Cycle. 2008. 7, 1020-1035.

89. Mizutani, K.; Ikeda, K.; Kawai, Y.; Yamori, Y. Resveratrol attenuates ovariectomy-induced hypertension and bone loss in stroke-prone spontaneously hypertensive rats. J Nutr Sci Vitaminol. 2000. 46(2), 78-83.

90. Antonio, A.M.; Druse, M.J. Antioxidants prevent ethanol-associated apoptosis in fetal rhombencephalic neurons. Brain Research. 2008.1204, 16-23.

91. Aruoma, O.I.; Sun, B.; Fujii, H.; Neergheen, V.S.; Bahorun, T.; Kang, K.S.; Sung, M.K. Low molecular proanthocyanidin dietary biofactor Oligonol: Its modulation of oxidative stress, bioefficacy, neuroprotection, food application and chemoprevention potentials. Biofactors. 2006. 27, 245-265.

92. Park, J.Y.; Kim, Y.; Im, J.A.; Lee, H. 2015. Oligonol suppresses lipid accumulation and improves insulin resistance in a palmitate-induced in HepG2 hepatocytes as a cellular steatosis model. BMC Complement Altern Med. 2015. 15.185.

93. Mendes, D.; Oliveira, M.M.; Moreira, P.I.; Coutinho, J.; Nunes, F.M.; Pereira, D.M.; Valentão, P.; Andrade, P.B.; Videira, R.A. Beneficial effects of white wine polyphenolsenriched diet on Alzheimer's disease-like pathology. The Journal of Nutritional Biochemistry. 2018. 55, 165-177.

94. Donmez, G.; Wang, D.; Cohen, D.; Guarente, L. SIRT1 suppresses beta-amyloid production by activating the alpha-secretase gene ADAM10. Cell. 2010.142, 320-332. 
95. Riviere, C.; Richard, T.; Quentin, L.; Krisa, S.; Mérillon, J.M.; Monti, J.P. Inhibitory activity of stilbenes on Alzheimer's $\beta$-amyloid fibrils in vitro. Bioorganic and Medicinal Chemistry. 2007.15, 1160-1167.

96. Marambaud, P.; Zhao, H.; Davies, P. Resveratrol promotes clearance of Alzheimer's disease amyloid- $\beta$ peptides. Journal of Biological Chemistry. 2005. 280, 37377-37382.

97. Liu, T.; Bitan, G. Modulating self-assembly of amyloidogenic proteins as a therapeutic approach for neurodegenerative diseases: strategies and mechanisms. ChemMedChem. 2012. 7, 359-374.

98. Zhou, X.; Chen, M.; Zeng, X.; Yang, J.; Deng, H.; Yi, L.; Mi, M. Resveratrol regulates mitochondrial reactive oxygen species homeostasis through Sirt3 signaling pathway in human vascular endothelial cells. Cell Death and Disease. 2014. 5, e1576.

99. Soares, D.G.; Andreazza, A.C.; Salvador, M. Sequestering ability of butylated hydroxytoluene, propyl gallate, resveratrol, and vitamins C and E against ABTS, DPPH, and hydroxyl free radicals in chemical and biological systems. Journal of Agricultural and Food Chemistry. 2003. 51, 1077-1080.

100. Gerszon, J.; Rodacka, A.; Puchała, M.. Antioxidant properties of resveratrol and its protective effects in neurodegenerative diseases. Adv. Cell Biology. 2014. 4, 97-117.

101. Desquiret-Dumas, V.; Gueguen, N.; Leman, G.; Baron, S.; Nivet-Antoine, V.; Chupin, S.; Chevrollier, A.; Vessières, E.; Ayer, A.; Ferré, M. Resveratrol induces a mitochondrial complex I-dependent increase in NADH oxidation responsible for sirtuin activation in liver cells. Journal of Biological Chemistry. 2013. 288, 36662-36675.

102. Donmez, G. The neurobiology of sirtuins and their role in neurodegeneration. Trends in Pharmacological Sciences. 2012. 33, 494-501.

103. Khan, R.S.; Fonseca-Kelly, Z.; Callinan, C.; Zuo, L.; Sachdeva, M.M.; Shindler, K.S.; SIRT1 activating compounds reduce oxidative stress and prevent cell death in neuronal cells. Frontiers in Cellular Neuroscience. 2012. 6, 63.

104. Kim, D.; Nguyen, M.D.; Dobbin, M.M.; Fischer, A.; Sananbenesi, F.; Rodgers, J.T.; Delalle, I.; Baur, J.A.; Sui, G.; Armour, S.M. SIRT1 deacetylase protects against neurodegeneration in models for Alzheimer's disease and amyotrophic lateral sclerosis. The EMBO Journal. 2007. 26, 3169-3179.

105. Capiralla, H.; Vingtdeux, V.; Zhao, H.; Sankowski, R.; Al-Abed, Y.; Davies, P.; Marambaud, P. Resveratrol mitigates lipopolysaccharide-and A $\beta$-mediated microglial inflammation by inhibiting the TLR4/NF- $\mathrm{KB} / \mathrm{STAT}$ signaling cascade. Journal of Neurochemistry. 2012. 120, 461-472.

106. Chen, M.I.; Yi, L.; Jin, X.; Liang, X.Y.; Zhou, Y.; Zhang, T.; Xie, Q.; Zhou, X.; Chang, H.; $\mathrm{Fu}$, Y.Y. Resveratrol attenuates vascular endothelial inflammation by inducing autophagy through the cAMP signaling pathway. Autophady. 2013. 9, 2033-2045.

107. Szewczuk, L.M.; Forti, L.; Stivala, L.A.; Penning, T.M. Resveratrol is a peroxidasemediated inactivator of COX-1 but not cox-2 a mechanistic approach to the design of cox-1 selective agents. Journal of Biological Chemistry. 2004. 279, 22727-22737.

108. Biesalski, H.K. Polyphenols and inflammation: basic interactions. Curr Opin Clin Nutr Metab Care. 2007. 10(6),724-728.

109. Milne, J.C.; Lambert, P.D.; Schenk, S.; Carney, D.P.; Smith, J.J.; Gagne, D.J.; Jin, L.; Boss, O.; Perni, R.B.; Vu, C.B. Small molecule activators of SIRT1 as therapeutics for the treatment of type 2 diabetes. Nature. 2007.450, 712. 
110. De La Lastra, C.A.; Villegas, I. Resveratrol as an antioxidant and pro-oxidant agent: mechanisms and clinical implications. Biochemical Society Transactions. 2007. 35, 1156-1160.

111. Islam, M.R.; Zaman, A.; Jahan, I.; Chakravorty, R.; Chakraborty, S. In silico QSAR analysis of quercetin reveals its potential as therapeutic drug for Alzheimer's disease. Journal of Young Pharmacists. 2013. 5, 173-179.

112. Ho, L.; Ferruzzi, M.G.; Janle, E.M.; Wang, J.; Gong, B.; Chen, T.Y.; Lobo, J.; Cooper, B.; Wu, Q.L.; Talcott, S.T. Identification of brain-targeted bioactive dietary quercetin-3-Oglucuronide as a novel intervention for Alzheimer's disease. The FASEB Journal. 2013. 27, 769-781

113. Ono, K.; Yoshiike, Y.; Takashima, A.; Hasegawa, K.; Naiki, H.; Yamada, M. Potent antiamyloidogenic and fibril-destabilizing effects of polyphenols in vitro: implications for the prevention and therapeutics of Alzheimer's disease. Journal of Neurochemistry. 2003. 87, 172-181.

114. Kanter, M.; Unsal, C.; Aktas, C.; Erboga, M. Neuroprotective effect of quercetin against oxidative damage and neuronal apoptosis caused by cadmium in hippocampus. Toxicology and Industrial Health. 2016. 32, 541-550.

115. Liu, C.M.; Zheng, G.H.; Cheng, C.; Sun, J.M. Quercetin protects mouse brain against leadinduced neurotoxicity. Journal of Agricultural and Food Chemistry. 2013. 61, 76307635.

116. Costa, L.G.; Garrick, J.M.; Roquè, P.J.; Pellacani, C. 2016. Mechanisms of neuroprotection by quercetin: counteracting oxidative stress and more. Oxidative Medicine and Cellular Longevity 2016. 2016, 2986796.

117. García-Mediavilla, V.; Crespo, I.; Collado, P.S.; Esteller, A.; Sánchez-Campos, S.; Tuñón, M.J.; González-Gallego, J. The anti-inflammatory flavones quercetin and kaempferol cause inhibition of inducible nitric oxide synthase, cyclooxygenase-2 and reactive $\mathrm{C}$ protein, and down-regulation of the nuclear factor kappaB pathway in Chang Liver cells. European journal of Pharmacology. 2007. 557, 221-229.

118. Hayakawa, M.; Itoh, M.; Ohta, K.; Li, S.; Ueda, M.; Wang, M.X.; Nishida, E.; Islam, S.; Suzuki, C.; Ohzawa, K. Quercetin reduces eIF2 $\alpha$ phosphorylation by GADD34 induction. Neurobiology of Aging. 2015. 36, 2509-2518.

119. Qin, X.Y.; Cheng, Y.; Yu, L.C. Potential protection of green tea polyphenols against intracellular amyloid beta-induced toxicity on primary cultured prefrontal cortical neurons of rats. Neuroscience Letters. 2012. 513, 170-173.

120. Mukai, R.; Shirai, Y.; Saito, N.; Fukuda, I.; Nishiumi, S.; Yoshida, K.I.; Ashida, H. Suppression mechanisms of flavonoids on aryl hydrocarbon receptor-mediated signal transduction. Archives of Biochemistry and Biophysics. 2010. 501, 134-141.

121. Ferreira, N.; Saraiva, M.J.; Almeida, M.R. Natural polyphenols inhibit different steps of the process of transthyretin (TTR) amyloid fibril formation. FEBS Letters. 2011. 585, 24242430.

122. Choi, Y.T.; Jung, C.H.; Lee, S-R.; Bae, J-H.; Baek, W-K.; Suh, M-H.; Park, J.; Park, C-W.; Suh, S-I. The green tea polyphenol (-)-epigallocatechin gallate attenuates $\beta$-amyloidinduced neurotoxicity in cultured hippocampal neurons. Life Sciences. 2001. 70, 603614.

123. Singh, N.A.; Mandal, A.K.A.; Khan, Z.A. Potential neuroprotective properties of epigallocatechin-3-gallate (EGCG). Nutrition Journal. 2015.15 (1), 60. 
124. Wobst, H.J.; Sharma, A.; Diamond, M.I.; Wanker, E.E.; Bieschke, J. The green tea polyphenol (-)-epigallocatechin gallate prevents the aggregation of tau protein into toxic oligomers at substoichiometric ratios. FEBS Letters. 2015. 589, 77-83.

125. Ahn, J.H.; Choi, J.W.; Choi, J.M.; Maeda, T.; Fujii, H.; Yokozawa, T.; Cho, E.J. Protective role of oligonol from oxidative stress-induced inflammation in C6 glial cell. Nutrition Research and Practice 2015, 9, 123-128.

126. Heymann, D.; Stern, Y.; Cosentino, S.; Tatarina-Nulman, O.; Dorrejo, J.N.; Gu,Y. The association between alcohol use and the progression of Alzheimer's disease. Curr Alzheimer Res. 2016. 13(12), 1356-1362

127. Koch, M.; Fitzpatrick, A.L.; Rapp, S.R.; Nahin, R.L.; Williamson, J.D.; Lopez, O.L.; DeKosky, S.T.; Kuller, L.H.; Mackey, R.H.; Mukamal, K.J.; Jensen, M.K.; Sink, K.M. Alcohol Consumption and Risk of Dementia and Cognitive Decline Among Older Adults With or Without Mild Cognitive Impairment. JAMA Netw Open. 2019. 2(9):e1910319.

128. Fernandez, G.M.; Savage, L.M. Adolescent binge ethanol exposure alters specific forebrain cholinergic cell populations and leads to selective functional deficits in the prefrontal cortex. Neuroscience. 2017. 361,129-143

129. Kok, E.H.; Karppinen, T.T.; Luoto, T.; Alafuzoff, I.; Karhunen, P.J. Beer Drinking Associates with Lower Burden of Amyloid Beta Aggregation in the Brain: Helsinki Sudden Death Series. Alcohol Clin. Exp Res. 2016, 40, 1473-1478.

130. Winkler, C.; Wirleitner, B.; Schroecksnadel, K.; Schennach, H.; Fuchs, D. Beer downregulates activated is isperipheral blood mononuclear cells in vitro. Int. Immunopharmacol. 2006. 6, 390-395.

131. Sasaoka, N.;Sakamoto, M.;Kanemori, S.;Kan, M.;Tsukano, C.;Takemoto,Y.;Kakizuka, A. Long-termoral administration of hop flower extracts mitigates Alzheimer phenotypes in mice. PLoS ONE 2014. 9, e87185.

132. Ano,Y.; Dohata, A.; Taniguchi,Y.; Hoshi, A.; Uchida, K.;Takashima,A.; Nakayama, H. Iso$\alpha$-acids, bitter components of beer, prevent inflammation and cognitive decline induced in a mouse model of Alzheimer's disease. J. Biol. Chem. 2017. 292, 3720-3728. 